\title{
A CARSIFICAÇÃO DA SERRA DA BOA VIAGEM: UM PROCESSO QUATERNÁRIO
}

\author{
Antónto Campar de Almeida *
}

Resumo

\begin{abstract}
A Serra da Boa Viagem (Figueira da Foz), apesar de baixa $(250 \mathrm{~m}$ ) e constituida dominantemente por calcários margosos, margas e arenitos do Jurássico, apresenta importante carsificação traduzida pela ocorrêtucia de lapiás, algares, grutas e dolinas. Estas proliferam, de modo mais ou menos ordenado, na plataforma superior da serra. São, na maior parte, em funil (simples ou embutidas noutras em concha). Teriam evoluído em duas fases de dolinização: a primeira logo após o recuo do mar pliocénico, que arrasara o cimo da serra, pelo menos em parte em processo cripto-cársico, sob as areias marinhas; a segunda depois de iniciado o soerguimento da serra e, em especial, com o desenvolvimento de algares e grutas, capazes de absorverem a água superficial.

Os periodos frios quaternários, pela menor temperatura da água e pela transformaçăo húmica da matéria orgânica resinosa superior, foran decerto mais propicios ao desenvolvimento do carso na Serra da Boa Viagen.
\end{abstract}

Palavras-chave: Carsificação, dolinas, Serra da Boa Viagem

Abstract

\begin{abstract}
Karstification of Mount Boa Viagem: a Quaternary process - Mount Boa Viagem (Figueira da Foz Center Littoral of Portugal) is a small relief $(250 \mathrm{~m})$ composed of Jurassic marly-limestones, marls and sandstones. It has an important surface karsification and a weak deep karstification. There are many dolines, but also «Karren», swallow-holes and caves. The dolines, most of which are either funnel-shaped, sometimes carved in dish-shaped dolines, are spread all over the upper platform, in two main directions $\mathrm{W}-\mathrm{E}$, in accordance with the geological structure, and $\mathrm{N}-\mathrm{S}$, as a result of faulting.

There were two phases in karst evolution: the first occurred just after the retreat of the upper Pliocene sea (which had originated the upper plation and deposited quartzose sands) was marked by the superficial chemical solution of the limestones that led to the formation of the dish-shaped dolines, probably still white bellow the sand; the second took place during and after the up-lift of the hill and specially after the development of swallow-holes and caves allowed the absorption of the supericial water and sediments - and eventually the development of the funnel-shaped dolines.

Considering factors like low temperatures and the resinous forest covering, it is very likely that it lappened mainly during the cold Quaternary periods.
\end{abstract}

Key-words: Karstification, dolines, Mount Boa Viagem.

A Serra da Boa Viagem, em sentido lato, é uma unidade morfológica com uma estrutura construída essencialmente por rochas carbonatadas jurássicas. Estas são seguidas, mais ou menos em concordância, por espessas unidades detríticas, também jurássicas e cretácicas inferiores, que constituem o flanco meridional da Serra. O conjunto acaba a ser fechado, no seu extremo meridional, mais uma vez por rochas carbonatadas do Cretácico médio, os Calcários da Costa de Ames (SOARES, 1966).

Apresenta uma estrutura monoclinal, com o pendor em direcção a Sul e a diminuir com a subida estratigráfica. Termina bruscamente a Norte por uma escarpa de falha que põe em contacto os calcários e margas do Lias com areias marinhas do Plistocénico médio a inferior, as Areias de Cantanhede (BARBosA et al., 1988).

As unidades líticas carbonatadas são dominantemente constituídas por calcáríos margosos, em ban- cadas ora estreitas ora espessas e a alternarem muitas vezes com leitos ou bancadas margosas, e por margas que chegam a ter grande importância nas unidades liásicas. $O$ maior teor calcário verifica-se na base de todo o conjunto, no extremo Norte da serra e, sobretudo, nas formações do Dogger e base do Malm que afloram na plataforma superior da Serra.

As grandes formas da Serra decalcam grosseiramente as formações geológicas. Às pequenas colinas calcárias da base do Liásico, a Norte, seguem-se áreas depressionadas das unidades mais margosas do Lias médio e superior, para se subir por escarpa para a plataforma superior com os calcários do Dogger e do Malm, a que se juntam os termos inferiores dos Arenitos da Boa Viagem (Malm superior).

Ora, foi precisamente sobre esta plataforma que se desenvolveu a maior parte das formas cársicas superficiais da Serra. 


\section{As formas cársicas}

São quatro as formas cársicas desenvolvidas na Serra da Boa Viagem: lapiás, dolinas, algares e grutas.

Embora não sejam visíveis em muitos locais, os lapiás, com tamanhos que raramente ultrapassam o meio metro de profundidade, estão decerto espalhados pela maior parte da superficie e vertentes do cimo da Serra. A razão dessa fraca visibilidade prende-se com a existência de uma cobertura arenosa fina (ALMEiDA, 1992), ou com depósitos de vertente, que os preencheram na totalidade. São, deste modo, lapiás enterrados (CUNHA, 1988) ou, quando parcialmente exumados, semi-enterrados. $\mathrm{O}$ arredondamento, ou mesmo inexistência, das arestas é o resultado da actuação prolongada e mais agressiva das águas retidas nas areias que os colmatam e dos ácidos provenientes da vegetação aí instalada.

Noutras superfícies também são notadas estas formas. Na plataforma do Farol (plataforma marinha pelos $90-100 \mathrm{~m}$ de altitude) fendas com mais de um metro de profundidade e preenchidas com areias e seixos arredondados do Depósito de Praia do Farol (ALMEIDA, 1992), também têm superficies adoçadas, em regra «seladas» por uma pequena camada argilosa proveniente da decomposição dos calcários. Podem ter-se desenvolvido posteriormente à deposição das areias de praia ou terem sido abertas pelo mar quando da construção da respectiva plataforma de erosão. A mesma problemática se levanta quanto aos profundos lapiás da superfície superior da Costeira de Salmanha (Calcários da Costa de Arnes, junto ao estuário do Mondego), também preenchidos por depósitos quartzareníticos grosseiros.

Os algares, muitas vezes algarochos, estão praticamente sempre associados a dolinas que drenam e põem em contacto com as galerias inferiores. A maioria está tapada por uma espécie de rolhão constituído por detritos orgânicos e sedimentares que the mascara a presença.

As grutas, de que não se conhece qualquer exploração ou estudo, deverão consistir em estreitas galerias ${ }^{\prime}$

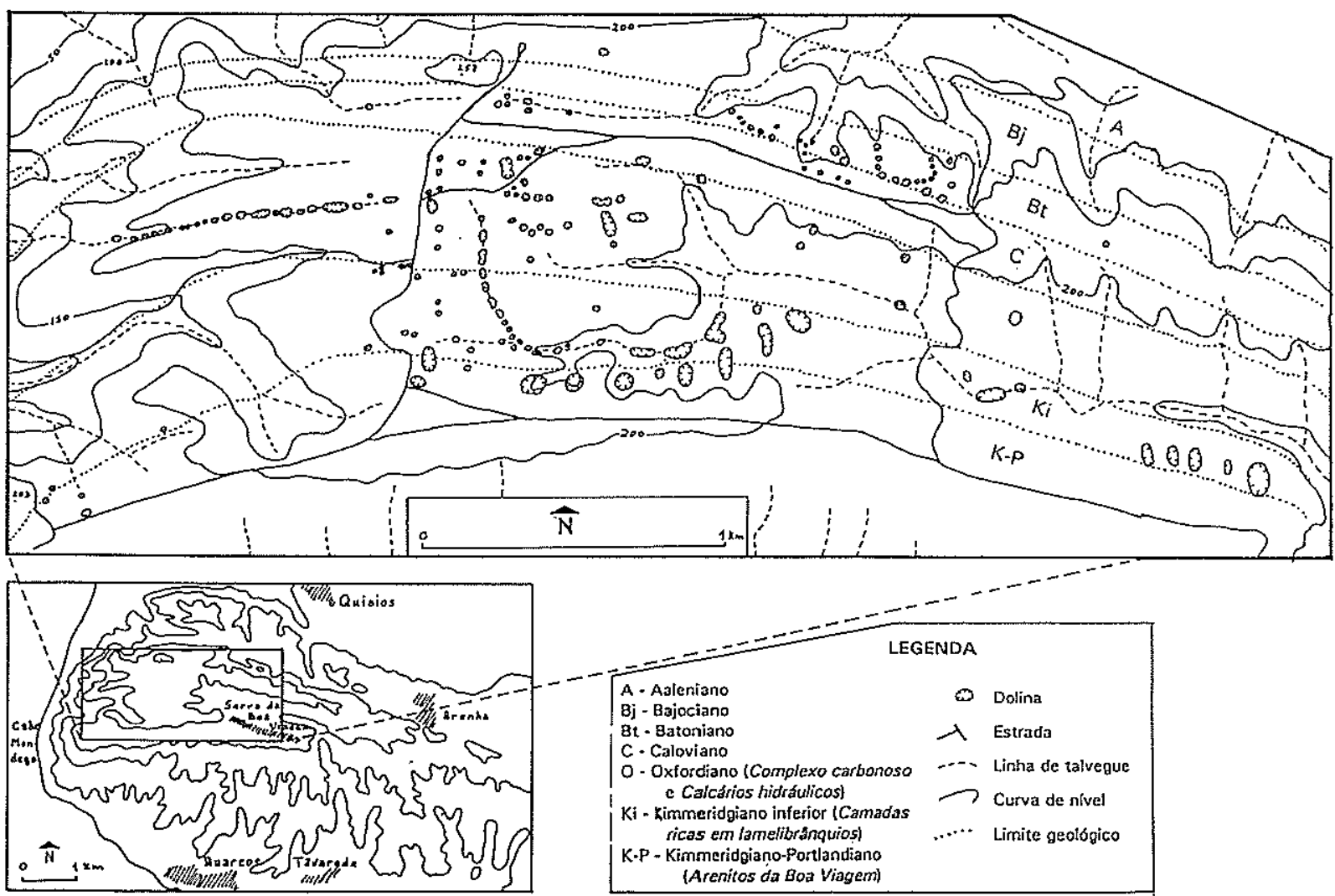

Fig. I - Distribuição das dolinas na Serra da Boa Viagem

Fig. 1 - Doline distribution on Boa Viagem Mountain.

\footnotetext{
I Uma ou outra galeria que aflora, como a Toca da Moura, numa cornija calcária a NE do Farol, mostra ser de dificil exploração pelo seu pequeno diâmetro e irregularidade.
} 
com disposição provável E-W, ou seja, paralela à estrutura geológica. É possível que não estejam ligadas em rede, atendendo à frequente ocorrência de bancadas margosas a alternarem com as bancadas de calcários margosos. Além disso, há referências, durante a exploração da mina de carvão, do aparecimento frequente de bolsadas de água retida no interior da serra. No entanto, houve-se por vezes a água a correr no fundo de algares o que comprova a sua existência.

As dolinas são as formas cársicas mais espectaculares da Serra (Fig. 1). Ultrapassam as 140 e são muito variadas em dimensão; as suas formas, no entanto, são pouco diversificadas (ALMEIDA, 1993). São de pequenas dimensões: desde os 2 a $3 \mathrm{~m}$ até aos $80 \mathrm{~m}$ de comprimento, e dos $0,5 \mathrm{~m}$ até aos $15 \mathrm{~m}$ de profundidade (quase dois terços têm menos de $15 \mathrm{~m}$ de comprimento e menos de $2 \mathrm{~m}$ de profundidade). Podem ser diferenciadas em três tipos de formas: $\mathrm{em}$ funil, em concha e dissimétricas. Com frequência, cerca de metade, apresenta embutimentos, em regra, dolinas em funil embutidas em dolinas em concha.

Para além da acção química de dissolução dos calcários, dominante numa primeira fase, a absorção ou sucção da cobertura arenosa através dos algarochos terá contribuído para a forma dominante em funil. Essa sequência de processos pode ser a explicação para o embutimento de dolinas em funil noutras em concha.

A posição que as dolinas ocupam está de acordo com duas direcções preferenciais: uma paralela à estrutura, grosso modo E-W, outra N-S. A primeira, litostratigráfica, salienta o papel da inclinação das camadas calcárias favoráveis à penetração da água e, sobretudo, da maior propensão para a carsificação de determinadas unidades. Destacam-se, no Dogger, os calcários margosos do Batoniano, e no Malm os calcários do Oxfordiano e do Kimeridgiano. As maiores dolinas surgem precisamente nesta última unidade, decerto graças à maior pureza dos seus calcários.

A segunda direcção, N-S, pelo alinhamento frequente das dolinas parece estar associada a fracturação transversal à Serra. Só assim se explica que importantes dolinas se tenham desenvolvido na base dos Arenitos da Boa Viagem (Kimeridgiano-Portlandiano), sem qualquer componente em carbonato de cálcio. A sua fracturação, permitindo a penetração da água e o aumento da superficie de contacto (CAMPY e MACAIRE, 1989), favoreceu o ataque do calcário subjacente, que seria acompanhado pela subsidência do material suprajacente.

Um aspecto curioso é o posicionamento da maioria das dolinas no fundo de antigos vales, ou valeiros agora suspensos. Significa isso uma sujeição da rede hidrográfica, desenvolvida na cobertura arenosa superior, à estrutura do substrato calcário em função da fracturação mas também da implementação de um criptocarso? Nos vales preenchidos por um rosário de dolinas, preservou-se, nos intervalos entre elas, a forma em berço primária. Também todas as grandes dolinas da margem direita da Ribeira de Tavarede, junto à povoação de Serra da Boa Viagem, se desenvolveram no fundo de valeiros que, perdendo a sua funcionalidade, se acham agora suspensos sobre o vale principal (ALMEIDA, 1997b).

\section{A carsificação}

As formas cársicas superficiais distribuem-se quase na totalidade na superficie superior da serra, a qual se acha agora inclinada entre os $257 \mathrm{~m}$ e os $170 \mathrm{~m}$. Tudo aponta para que o agente afeiçoador desta superfície tenha sido o mar. Ela contém um depósito areno-pelítico pouco espesso (máximo $2,5 \mathrm{~m}$ ), descontínuo, restando apenas nos níveis mais elevados, de composição homométrica, quartzoso e rico em micas (Almeida, 1992).

Nalguns pontos da superfície, e em especial em fendas cársicas, ocorrem areias avermelhadas com seixos de quartzo e quartzito bem rolados que poderão ser o que resta do depósito marinho correlativo da superfície de erosão. A posição da superficie e uma certa semelhança dos seus depósitos com depósitos tidos como pliocénicos, mais a oriente (por exemplo as Areias de Cordinhã-BARBosa et al., 1988) leva a admitir ser também de idade pliocénica.

Deste modo, é possível que a carsificação da Serra se tenha iniciado só posteriormente ao Pliocénico superior, admitindo que aquela não tenha estado exposta antes e tenha sido «selada» por aquele depósito gresoso, correlativo do seu aplanamento superior. Não obstante, a existência das fendas largas, por vezes com alguns metros de profundidade, preenchidas pelo depósito arenoso avermelhado e embalando seixos bem rolados, pode levantar a dúvida se não seriam já formas cársicas desenvolvidas após a retirada do mar e que se colmatariam com material do depósito superior ainda não totalmente levado da superfície; ou então, seriam apenas formas abertas pela abrasão marinha no seu desmantelamento da rocha e construção da respectiva plataforma.

É provável que o ataque químico do calcário se tenha iniciado ainda antes do depósito suprajacente ter sido destruído, quase na totalidade, pela erosão. A permeabilidade das areias possibilitaria o desencadear dum processo criptocársico que levaria ao esboçar e alargar das futuras dolinas, segundo as direcções preferenciais já referidas. Mas então, nesse 
caso, seria de esperar que houvesse restos desse depósito superior conservados nalgumas das dolinas e não se deu conta disso ${ }^{2}$.

De qualquer modo, a primeira fase de dolinização deve ter sido por um processo essencialmente de dissolução. Apesar de alguns vales do cimo da Serra terem os seus fundos cravejados de dolinas, se nos abstrairmos destas, o seu perfil transversal, com fundo em berço ou aplanado, assim como o perfil longitudinal, com fraco declive, mas sempre inclinado para jusante, indiciam que antes das dolinas controlarem a circulação da água, esta teria corrido aqueles vales, afeiçoando-lhes o fundo e as vertentes. Isto não obsta a que as dolinas não estivessem já em evolução, facilitando, porventura, o encaixe do próprio vale; não conteriam ainda algarochos, nem estariam ligadas a galerias interiores.

Entretanto, o soerguimento da Serra ${ }^{3}$ veio permitir que, pouco a pouco, a carsificação começasse a penetrar no seu interior, facilitada, aliás, pela disposição fortemente inclinada das bancadas, possibilitando a formação de pequenas galerias que começaram a poder absorver parte da água caída à superfície, assim como de alguns dos sedimentos aí existentes. Isto levou a uma desorganização da circulação superficial e a um aumento na rapidez de evolução das próprias dolinas.

Periodos houve em que o fundo das vertentes e as próprias dolinas teriam recebido um afluxo detrítico particularmente importante, como parece testemunhar a ocorrência generalizada do depósito areno-pelítico superior em qualquer posição topográfica e que, por vezes, se intercala com depósitos paraconglomeráticos calcários, de matriz também arenosa fina. Isto faz pensar numa situação semelhante, talvez mesmo correlativa, da que levou à construção dos Depósitos de vertente no Cabo Mondego (SOARES et al., 1993), ou seja, a actuação de processos morfogenéticos em ambiente frio, como a gelifracção, a solifluxão e a eolização, por vezes em simultâneo.

As galerias passam a comandar a evolução das dolinas ao serem capazes de, nos momentos de maior concentração superficial de água, absorverem por colapso, ou lenta infilttração, o material de cobertura que atapetava o fundo das depressões. A escorrência e a diminuição da espessura do manto de cobertura, expondo a rocha subjacente ao mais fácil ataque das águas, exercem o trabalho restante de evolução das dolinas. Quando presentes algarochos, a tendência passa a ser de um desenvolvimento em profundidade em detrimento do desenvolvimento lateral, daí a frequência de dolinas em funil e de dolinas embutidas noutras maiores.

O processo continua, embora os colapsos ocorram episodicamente. Ainda há poucos anos, no Inverno, se abriu um buraco com $4 \mathrm{~m}$ de profundidade por $6 \mathrm{~m}$ de diâmetro, no fundo do valeiro a ocidente da Bandeira, com exposição da boca do algar que tem cerca de $1 \mathrm{~m}$ de diâmetro, sendo engolidos mais de $2 \mathrm{~m}$ de espessura de sedimentos e parcialmente duas árvores. Com o provável entulhamento da boca do algar e a previsível evolução das paredes verticais actuais para vertentes inclinadas, por movimentos de massa ou simples escorrência, desenvolver-se-á uma dolina em funil (ALMEIDA, 1997a).

Não tão recentes como esta, podem ser cinco pequenas dolinas existentes na plataforma do Farol (90-100 m de altitude), junto à casa da Guarda, aparentemente originadas por abatimento ou subsidência dos sedimentos arenosos superiores, na sequência da exploração da mina de carvão do Cabo Mondego, iniciada em meados do séc. XVIII. Não se exclui, no entanto, a possibilidade de terem tido uma causa natural, tal como se preconiza para as dolinas do cimo da Serra (Almeida, 1997b).

\section{Conclusão}

Mesmo admitindo como quaternário o desenvolvimento da carsificação da Serra da Boa Viagem, pode pôr-se sempre a questão de quando é que o fenómeno foi dominante, nos períodos frios ou nos quentes?

Apesar de neste momento continuar o processo, como comprovam os colapsos e subsidências que se vão verificando, não deve custar a admitir que foi nos períodos mais frios que a carsifícação foi mais rápida. A água em circulação era mais fria, portanto mais agressiva (JENNINGS, 1985), mas o próprio coberto vegetal também seria favorável a esse maior ataque. Pelo menos no último período glaciário, na costa ocidental centro e norte de Portugal, há indícios de ter havido uma cobertura florestal, contínua ou descontínua, de pinheiros silvestres (Gransa et al., 1996). A Serra da Boa Viagem, pelo menos na sua plataforma superior, graças à cobertura arenosa, decerto que

2 A não ser que o depósito superior referido fosse constituido, pelo menos na sua base, pelo areno-pelítico agora existente no cino da Serra. Esse, sen dúvida, surge em praticamente todas as dolinas, embora de forma pelicular. Também é possivel que, mesmo que outro tipo de depósito ficasse a preencher as dolinas iniciais estas, ao evoluirem posteriommente sob o condicionamento de algarochos, fossen incapazes de o reservar, pela absorção através daqueles vazios criados.

3 Aceitando-se que o depósito superior é o equivalente lateral das Areias de Cordinhã, pliocénicas, então a Serra da Boa Viagem ter-se-ia erguido mais de $100 \mathrm{~m}$ durante o Quaternário. J. CABRAL (1993) aponta-lhe como elevação média provável, durante o Quaternário, 0,05 a $0,2 \mathrm{~mm} / \mathrm{ano}$. 
também possuiria uma cobertura florestal desse tipo. $\mathrm{O}$ húmus formado, mor, forneceria grande quantidade de ácidos orgânicos solúveis que, infiltrados através do solo e das areias subjacentes atacariam com grande agressividade o calcário inferior.

Nos períodos interglaciários, para além das águas mais quentes, a cobertura vegetal, à imagem do que se passa agora, seria dominada por florestas de folhosas com formação de húmus mull, muito menos agressivo para os calcários e, portanto, com menor velocidade de carsificação.

\section{REFERÊNCIAS BIBLIOGRÁFICAS}

ALMEidA, A. Campar (1992) - «Os depósitos superiores da Serra da Boa Viagem e seu significado». Cadernos de Geografia, Coimbra, 9, pp. 151-162.

AlmEIDA, A. Campar (1993) - «Dolinização na Serra da Boa Viagem». Actas da 3." Reunião do Quaternário Ibérico. Coimbra, pp. 135-139.

Almiba, A. Campar (1997a) - Dunas de Quiaios, Gândara e Serro da Boa Viagem. Uma abordagem ecológica da paisagem. Lisboa, F. C. Gulbenkian/JNICT, 321 p.

Al.MEIDA, A. Campar (1997b) - «Geomorfologia das serras da Boa Viagem e Alhadas». Actas do Seminário O Baixo Mon-dego
Organização geossistémica e recursos naturais, Coimbra, pp. 51-60.

BARBOSA, B. P.; SOARES, A. F; ROCHA, R. B.; MANUPELlA, G.; HENRIQues, M. H. (1988) - Noticia explicativa da Folha 19-ACantanhede - da Carta Geológica de Portugal. Lisboa, Serv. Geol. Portugal, $46 \mathrm{p}$.

CABral, João M. L. C. (1993)-Neotectónica de Portugal Continental. Lishoa, Fac. Ciências, Tese de doutoramento, $435 \mathrm{p}$

CAMPY, M. \& MACAIRE, J. J. (1989)-Géologie des formations superficielles. Géodynamique-faciès-utilisation. Paris, Masson, 433 p.

CunHA, Lúcio (1988) - As serras calcárias de Condeixa - SicóAlvaiúzere. Estudo de Geomorfologia. Coimbra, Fac. Letras, Tese de doutoramento, $329 \mathrm{p}$.

Granja, H. M., Carvalho, G. S., De Groot, T., Monge Soares, A. \& PARISH (1996) - «Geochronology and the Recent Geomor-phological Evolution of the Northwest Coastal Zone of Portugal». In J. Taussik \& J. Mitchell (eds.) - Parthership in Coastal Zone Management, Cardigan, Samara Publishing Ltd., pp. 297-308.

JENNINGS, J. N. (1985)-Karst Geomorphology. Oxford, Basil Blackwell, 293 p.

SOARES, A. Ferreira (1966) - «Estudo das formações pós-Jurássicas da região de entre Sargento-Mor e Montemor-o-Velho (margem direita do rio Mondego)». Memórias e Noticias, Coimbra, 62, pp. 1-343.

SoAris, A. F.; Cunha, L.; Marques, J. F.; Almeida, A. C.; Lapa, M. L. R. (1993) - «Depósitos de vertente no Cabo Mondego. Integração no modelo evolutivo do Quaternário do Baixo Mondego". Actas da ll/ Reuniäo do Quaternario Ibérico, Coimbra, pp. 199-208. 